\title{
Coronary artery vein grafting in a case of Ehlers-Danlos syndrome
}

\author{
ANDREW REDINGTON, JANE MCCUE, STUART LENNOX \\ From the Departments of Cardiology and Cardiothoracic Surgery, Brompton Hospital, London
}

SUMmARY A 64 year old man with Ehlers-Danlos syndrome type 2 was admitted to hospital with severe angina of effort. Aortocoronary vein grafting was performed successfully.

Ehlers-Danlos syndrome is an uncommon inherited connective tissue disorder. The main features are joint hypermobility, skin hyperelasticity, easy bruising, "cigarette paper scarring," and subcutaneous pseudotumour formation in combination with ocular, skeletal, and cardiovascular abnormalities. At present 12 types are described. Ehlers-Danlos syndrome type 2 is generally considered to be a mild form of the disorder with autosomal dominant inheritance. ${ }^{1}$ Skin hyperelasticity may be very pronounced in these patients. The cardiovascular abnormalities so far described are related to defects in collagen synthesis. The most common abnormalities are mitral and tricuspid valve prolapse, dilatation of the aortic root and the sinuses of Valsalva, atrial and ventricular septal defects, and valve stenosis and regurgitation. ${ }^{23}$ Cardiac surgery in these patients presents obvious technical difficulties, and because of the high incidence of postoperative complications and the high mortality ${ }^{4-7}$ corrective surgery has rarely been performed. Until now atheromatous coronary artery disease has not been reported in patients with the Ehler-Danlos syndrome. We report what we believe to be the first instance of successful coronary artery vein grafting in this condition.

\section{Case report}

A 64 year old man, who had been a lifelong cigarette smoker, presented with a nine month history of progressive angina of effort. Hyperextensible skin had been noted since childhood with easy bruising in response to minor trauma. On one occasion at the age of 12 years surgical evacuation of a tibial haematoma was required. In adult life uncomplicated left inguinal herniorrhaphy was performed. Ehlers-Danlos syn-

Requests for reprints to Dr J L McCue, Queen Elizabeth Hospital for Children, Hackney Road, London E2. drome type 2 had previously been diagnosed on the basis of clinical findings in his mother, two of three siblings, his son and daughter, and one grandchild.

On physical examination he was $1.65 \mathrm{~m}$ in height, weighed $74.5 \mathrm{~kg}$, and had no marfanoid features. The skin was hyperextensible with a velvety feel and was lax around the neck and elbows (Fig. 1). Atropic "cigarette paper" scars were visible over the anterior surface of both tibiae (Fig. 2) and the site of his previous herniorrhaphy. Mild hypermobility of the finger joints was noted. There was no evidence of eye involvement or periodontitis. Examination of the cardiovascular system showed evidence of peripheral vascular disease with absent pedal pulses bilaterally. He was normotensive. On auscultation no murmurs could be heard.

Chest $x$ ray films, electrocardiograms, and echocardiograms were normal. Coronary angiography via the right femoral route showed severe stenoses of the proximal left anterior descending and right coronary arteries. Left ventricular angiography was normal with no evidence of mitral regurgitation and aortography was unremarkable. After this procedure there was extensive bruising around the puncture site extending from the umbilicus to the right knee. Skin biopsy showed a delicate collagen network of the papillary and reticular dermis with some thickened elastic fibres, which was compatible with a diagnosis of Ehlers-Danlos syndrome. The DNA pattern appeared normal.

In view of his disabling symptoms, which were resistant to medical treatment, coronary artery vein grafting was performed via a median sternotomy. Pronounced connective tissue friability was noted, and both pleural cavities became widely opened. Cardiopulmonary bypass was established with right atrial-inferior vena cava and aortic cannulation. Slightly dilated long saphenous veins were removed from both legs. The left coronary artery was severely 


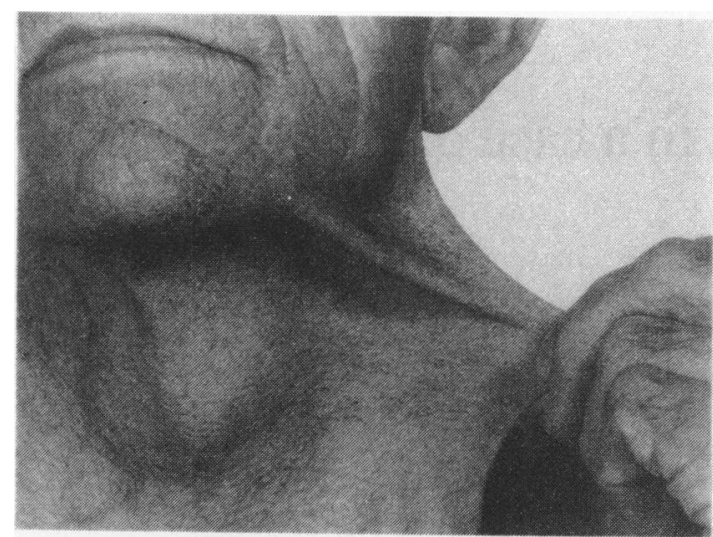

Fig. 1 Hyperextensibility of the skin around the neck in a patient with Ehlers-Danlos syndrome.

diseased, and distal endarterectomy was performed. Uncomplicated grafting to both left and right coronary arteries was then completed. During anastomosis of the proximal ends of the grafts to the aorta, however, there was considerable bleeding from the aortic cannulation site. The aortic wall in this area was friable and had to be repaired with multiple Teflon pledgets. This was the only evidence of severe intraoperative bleeding, and the patient was returned to the intensive care ward with bilateral pleural and mediastinal drains in situ.

Immediate postoperative recovery was satisfactory with average blood loss. He was extubated after four hours, and the pleural drains were removed after 14 hours after draining a total of $680 \mathrm{ml}$. After transfer to the general ward 24 hours postoperatively extensive

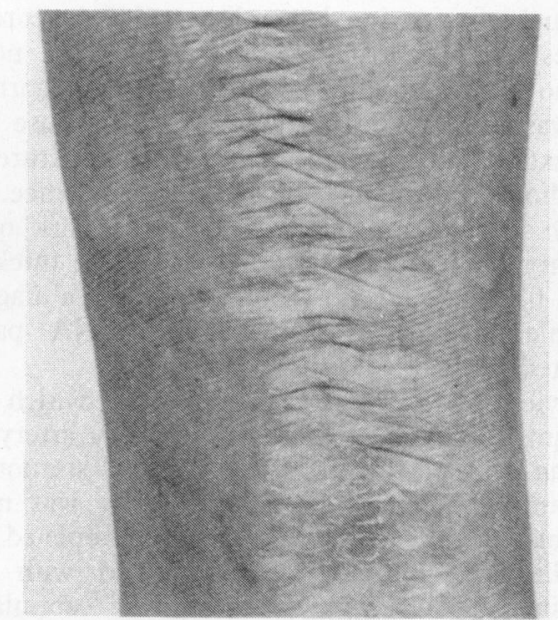

Fig. 2 Atropic "cigarette paper" scars on anterior surface of tibia. chest wall bruising became obvious. Thereafter he followed an uneventful postoperative course with minimal drainage from the mediastinal drain, which was removed on the fourth postoperative day. The leg and chest wounds healed satisfactorily. Sixteen days after the operation he was discharged back to the referring hospital. At three months the patient was free of angina and resuming normal activities.

\section{Discussion}

Assessment of patients with Ehlers-Danlos syndrome for cardiac surgery is not straightforward. Percutaneous angiography can be hazardous. In this case it was complicated by severe bruising, but more serious complications include arterial rupture, false aneurysm, arteriovenous fistula formation, and death. ${ }^{89}$ Surgery should therefore be restricted to those patients with a specific indication for surgery and pursued with great caution. Defects in platelet-collagen interaction, with decreased platelet aggregation to collagen, ${ }^{1011}$ account in part for the easy bruising and vascular complications seen in this condition. Coronary atheroma is a common condition in the general population but has not been reported in the EhlersDanlos syndrome, and this platelet-collagen defect may account for the decreased incidence of atheromatous heart disease in these patients. An angiographic cross sectional study, although difficult to justify, will be needed to substantiate this clinical impression. Nevertheless, our patient had evidence of severe coronary atheroma requiring coronary artery vein grafting.

This case illustrates some of the difficulties encountered during surgery in Ehlers-Danlos syndrome. Arterial repair and haemostasis may be complicated by excessive tissue friability with the further problems of sutures tearing out and trauma due to arterial cross clamping and cannulation. Ventriculotomy, although not performed in this case, may also be difficult to repair. ${ }^{712} \mathrm{It}$ is interesting to note that both pleura were friable and became widely opened. This observation may correlate with the increased incidence of spontaneous pneumothorax seen in Ehlers-Danlos syndrome. Extensive chest wall bruising occurred and can be expected in these patients after median sternotomy. Poor wound healing and wound dehiscence, although well recognised complications, did not take place.

At present Ehlers-Danlos typing is based largely on the clinical features, although up to $50 \%$ of cases are difficult to assign to a specific type. ${ }^{13}$ As increasingly complex biochemical and other forms of analysis become available definite guidelines as to suitability for cardiac surgery may be drawn up on the basis of 
preoperative skin biopsy and typing.

We would like to thank Dr F M Pope for his assistance in typing this patient.

\section{References}

1 Beighton P. The Ehlers-Danlos syndrome. London: Heinemann, 1970.

2 Antani J, Srinivas HV. Ehlers-Danlos syndrome and cardiovascular abnormalities. Chest 1973; 63: 214-7.

3 Leier CV, Call TD, Fulkerson PK, Wooley CF. The spectrum of cardiac defects in the Ehlers-Danlos syndrome, types I and III. Anen Intern Med 1980; 92: 171-8.

4 Rybka FJ, O'Hara ET. Surgical significance of the Ehlers-Danlos syndrome. Am $\mathcal{F}$ Surg 1967; 113: 431-4.

5 Wesley JR, Mahour GH, Woolley MM. Multiple surgical problems in two patients with Ehlers-Danlos syndrome. Surgery 1980; 87: 319-24.

6 Frieden J, Hurwitt ES, Leader E. Ruptured aortic cusp associated with an heritable disorder of connective tissue. Am F Med 1962; 33: 615-8.
7 Edmondson P, Nellen M, Ross DN. Aortic valve replacement in a case of Ehlers-Danlos syndrome. $\mathrm{Br}$ Heart 7 1979; 42: 103-5.

8 Mirza FH, Smith PL, Lim WN. Multiple aneurysms in a patient with Ehlers-Danlos syndrome: angiography without sequelae. AfR 1979; 132: 993-5.

9 Wright CB, Lamberth WC, Ponseti IV, Hanson J. Successful management of popliteal arterial disruption in Ehlers-Danlos syndrome. Surgery 1979; 85: 708-12.

10 Chun PKC, Flannery EP, Bowen TE. Open-heart surgery in patients with hematologic disorders. Am Heart f 1983; 105: 835-42.

11 Karaca M, Cronberg L, Nilsson IM. Abnormal plateletcollagen reaction in the Ehlers-Danlos syndrome. Scand f Haematol 1972; 9: 465-9.

12 Marquez J, Juffé A, Rufilanchas JJ, Maitre M, Artaza M. Successful correction of valvular and fibromuscular subpulmonary ring stenosis in a patient with EhlersDanlos syndrome. F Cardiovasc Surg (Torino) 1978; 19: 271-6.

13 Salem O, Tomecki KJ. Ehlers-Danlos syndrome type II (mitis). Cleve Clin $Q$ 1982; 49: 265-8.

\section{Notices}

\section{British Cardiac Society}

The Autumn Meeting will be held at the Wembley Conference Centre, London, on 3 and 4 December 1984 , and the closing date for receipt of abstracts will be 15 August 1984.

The Annual General Meeting for 1985 will take place in Birmingham on 17 and 18 April 1985, and the closing date for receipt of abstracts will be 8 January 1985.

\section{Can we have safer cigarettes?}

A conference will be held on 8 November 1984 at the Bloomsbury Crest Hotel, London. Further information may be obtained from the chest, Heart and Stroke Association, Tavistock House North, Tavistock Square, London WC1H 9JE. 